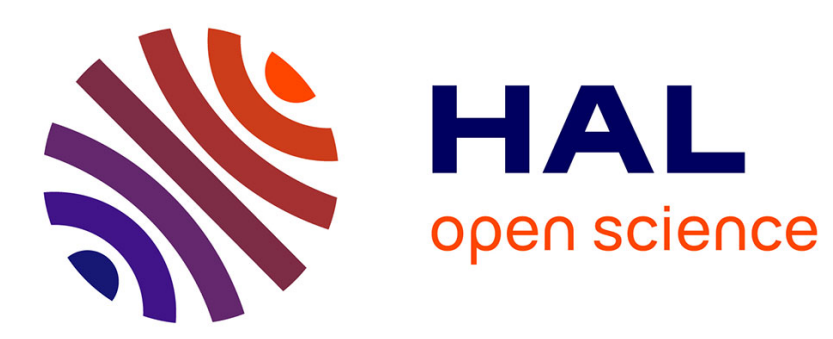

\title{
Realization and modeling of a 27-GHz integrated passively mode-locked ring laser
}

Yohan Barbarin, E.A.J.M. Bente, M.J.R. Heck, J.H. den Besten, G. Guidi, Y.S. Oei, J.J.M. Binsma, M.K. Smit

\section{- To cite this version:}

Yohan Barbarin, E.A.J.M. Bente, M.J.R. Heck, J.H. den Besten, G. Guidi, et al.. Realization and modeling of a 27-GHz integrated passively mode-locked ring laser. IEEE Photonics Technology Letters, 2005, 17 (11), pp.2277-2279. 10.1109/LPT.2005.857228 . hal-02550225

\section{HAL Id: hal-02550225 \\ https://hal.science/hal-02550225}

Submitted on 22 Apr 2020

HAL is a multi-disciplinary open access archive for the deposit and dissemination of scientific research documents, whether they are published or not. The documents may come from teaching and research institutions in France or abroad, or from public or private research centers.
L'archive ouverte pluridisciplinaire HAL, est destinée au dépôt et à la diffusion de documents scientifiques de niveau recherche, publiés ou non, émanant des établissements d'enseignement et de recherche français ou étrangers, des laboratoires publics ou privés. 


\title{
Realization and Modeling of a $27 \mathrm{GHz}$ Integrated Passively Modelocked Ring Laser
}

\author{
Y. Barbarin, E.A.J.M Bente, M.J.R. Heck, J.H. den Besten, G. Guidi, Y.S Oei, J.J.M. Binsma \\ and M.K. Smit
}

\begin{abstract}
We present a realization and the modeling of a $27 \mathrm{GHz}$ integrated extended cavity ring laser that is passively modelocked. The modelocked ring laser is fabricated with activepassive integration. Experimental results show that internal reflections are the major factor affecting operation stability. $\mathrm{CW}$, self-pulsating and in small windows of operation modelocked regimes have been observed. Similar regimes have been observed in our bidirectional laser model. This model describes the semiconductor amplifier and the saturable absorber using rate equations. Our experimental and theoretical results are compared and discussed.
\end{abstract}

Index Terms - mode locked lasers, semiconductor waveguide, integrated optics, active-passive integration.

\section{INTRODUCTION}

$M$ odelocked lasers are key components for high bit rate telecommunication. Optical Time Domain Multiplexing (OTDM) is a solution to increase the rate of a WDM channel up to $160 \mathrm{Gbit} / \mathrm{s}$ or higher. The application of OTDM requires clock recovery and clock division for demultiplexing the signals. In our project we are developing an All Optical Clock Recovery (AOCR) device based on an injection seeded passively ModeLocked Laser (MLL). For this application the ring configuration has two advantages. Firstly, the repetition rate of the laser is controlled accurately by photolithography as opposed to a device with cleaved facet mirrors. Secondly the ring laser configuration is more suitable for the injection seeding process that is at the centre of the AOCR. The buttjoint active-passive integration technology [1] allows to have two waveguides types, one for active and one for passive elements. We used this technology to make the laser design suitable for further integration with other devices such as an all-optical switch. In this paper we present the first integrated extended cavity passively modelocked ring laser using activepassive integration and its modeling.

Manuscript received 2005. This research is supported by the Dutch NRC Photonics program and the Towards Freeband Communication Impulse of the technology program of the Dutch Ministry of Economic Affairs.

Y. Barbarin, E.A.J.M Bente, M.J.R. Heck, J.H. den Besten, G. Guidi, Y.S Oei and M.K. Smit are with COBRA, Eindhoven University of Technology Den Dolech 2, P.O. Box 513, 5600 MB, Eindhoven, The Netherlands (e-mail: y.barbarin@tue.nl).

J.J.M. Binsma was with JDS Uniphase, Prof. Holstlaan 4, NL-5656 AA, Eindhoven, The Netherlands.

\section{MODELOCKED LASER DEVICE}

A modelocked ring laser has been realized in the $\mathrm{InP} / \mathrm{InGaAsP}$ material system with active-passive integration. A picture of the fabricated device is given in Fig. 1; waveguides are visible as dark lines. To better understand the layout, one must realize that the positions and sizes of the active regions were predetermined through the re-growth process. The white bar at the bottom is the metallization of a $500 \mu \mathrm{m}$ long amplifier. To realize a $30 \mu \mathrm{m}$ saturable absorber a waveguide was positioned to cross at an angle the second active area. Light is coupled out from the ring cavity using a Multi-Mode Interference Coupler (MMI). For this design, the ring laser Free Spectral Range (FSR) could not be over $27 \mathrm{GHz}$ due to the minimum ring length that could be fitted through the active regions.

Deep and shallow etched waveguides were used in order to combine deep etched waveguides for small $(100 \mu \mathrm{m})$ bending radii with low propagation loss in shallow waveguides. To reduce facet reflectivity, output waveguides (not visible in the Fig. 1) are angled by $7^{\circ}$ with respect to the facets normal and contain mode filters [2].

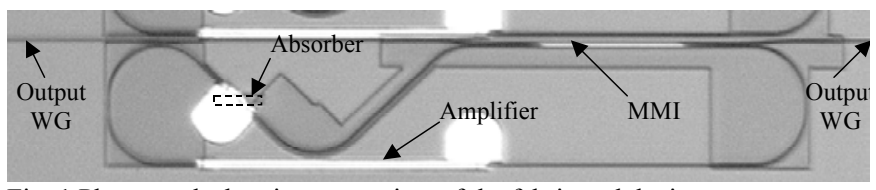

Fig. 1 Photograph showing a top-view of the fabricated device.

\section{MODELLING}

To simulate the performance of our device, a numerical bidirectional model has been developed. The amplifier and the absorber are described using rate equations. The ring is divided into 1500 segments that are equal in optical length. (Fig. 2). Every $25 \mathrm{fs}$ the photon densities (CW and $\mathrm{CCW}$ ) and carrier densities are calculated for all segments. Then the photon densities are transferred to the next segments and the carrier density values are saved in active segments for the next step. A digital Bessel filter (14th order) simulates the gain bandwidth limitation. The filter transmission spectrum is close to the measured gain spectrum (Fig. 3) and it is numerically stable. Small reflections $\left(2 \cdot 10^{-4}\right)$ at the different active passive butt-joints interfaces [3] and at the MMI inputs [4] are included in the modeling. 


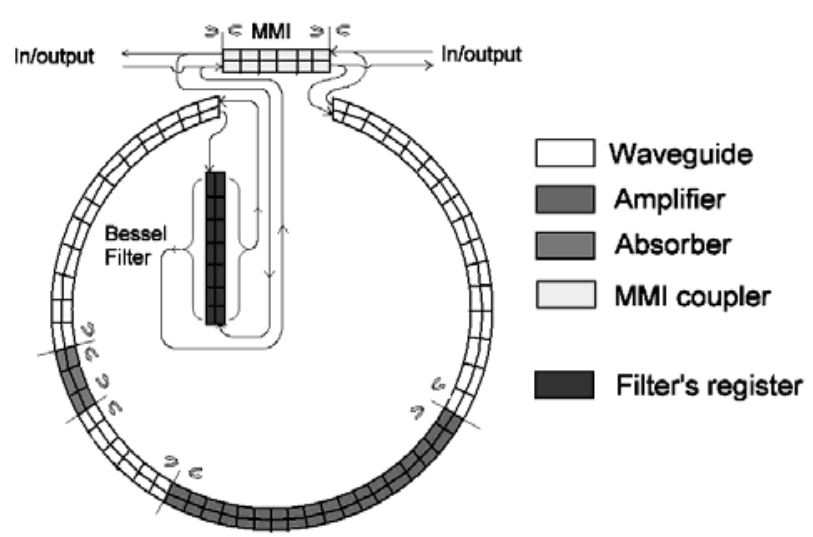

Fig.2: Structure of the representation of the MLL in the model.

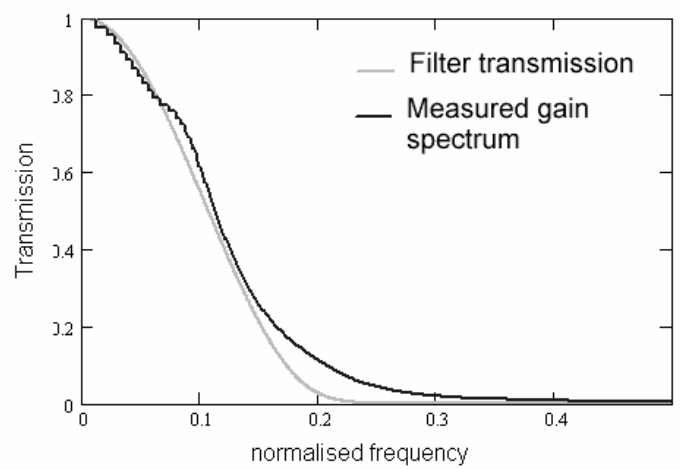

Fig.3 Spectra of the spontaneous emission from a similar amplifier and the transmission of the digital Bessel filter used in the model.

The SOA is described using the standard rate equations and the logarithmic gain-current density validated in [5].

$$
\begin{aligned}
\frac{\delta P^{C W, C C W}(x, t)}{\delta t}=P^{C W}(x, t) \cdot\left[\sigma_{a m p} \cdot \ln \left(\frac{\mathrm{N}(x, t)}{N 0}\right) \cdot V g \cdot \Gamma-\frac{\operatorname{Loss}_{\text {seg }}(\mathrm{N}(x, t))}{\tau_{s e g}}\right] & +\mathrm{B} \cdot \Gamma \cdot \mathrm{N}(x, t)^{2} \cdot \beta \\
\frac{\delta \mathrm{N}(x, t)}{\delta t}=- & {\left[P^{C W}(x, t)+P^{C C W}(x, t)\right] \cdot \sigma_{a m p} \cdot \ln \left(\frac{\mathrm{N}(x, t)}{N 0}\right) \cdot V g } \\
& -\frac{\mathrm{N}}{\tau_{\text {carAmp }}}-\mathrm{B} \cdot \mathrm{N}(x, t)^{2}-C \cdot \mathrm{N}(x, t)^{3}+W
\end{aligned}
$$

Here $P^{C W, C C W}$ are the Clock Wise and Counter Clock Wise photon densities, $N$ is the active region carrier density, $W$ is the carrier density generated in the active layer by the injection current, $N_{0}$ is the carrier transparency density, $V g$ is the group velocity, $\sigma_{a m p}$ is the linear gain coefficient, $\tau_{\text {carAmp }}$ is the carrier lifetime, $B$ is the bimolecular recombination coefficient, $C$ is the Auger recombination coefficient, $\Gamma$ is the confinement factor, Loss $_{\text {seg }}$ is the sum of the different losses for one segment (the scattering loss, the free carrier loss in the cladding, and the free carrier absorption within the active layer which depends of the carrier density), $\tau_{\text {seg }}$ is the time segment and $\beta$ is the spontaneous emission coupling factor.

The absorber is a short SOA that is reversely biased. It is described with the same rate equations as the amplifier without carrier injection. The carrier lifetime of the absorber depends of the reverse bias applied, but the relation has not been implemented in our model. Self-phase modulation effects and coherent effects in the absorber are not included.

\section{EXPERIMENTAL AND SIMULATION RESULTS}

First experimental results of the modelocked ring laser depicted in Fig. 1 showed that small reflections in the cavity have a large influence on the spectrum of the laser. Small reflections are expected at the active-passive interface and at the inputs of the MMI coupler. The spectrum varies significantly with temperature and current in the SOA due the small changes in the optical path length between reflection points. This makes the laser operating in very small operating windows.

Using our numerical model, we have calculated the performance of the ring laser. A simulation of the self-starting laser is plotted in Fig. 4. The model shows bidirectional operation of the laser like observed from the real device. The simulation starts with relaxation oscillations and modelocking sets in more slowly. The difference in intensity between the clockwise $(\mathrm{CW})$ and counterCW $(\mathrm{CCW})$ output is determined by the order of the amplifier, absorber and output coupler in the cavity. A steady modelocked state is reached after $16 \mathrm{~ns}$ (450 roundtrips). As depicted in Fig. 5, in our model a modelocked state is easily achieved for a wide range of parameters, as opposed to the experimental observations. However continuous wave (CW), self-pulsating and modelocking operation did show up in the experiments and in the simulations. We attribute this difference to not having included the self-phase modulation in the model and having fixed optical path lengths between reflections.

According to the model the laser starts to be modelocked for an absorber carrier lifetime shorter than $30 \mathrm{ps}$. For a carrier lifetime over $14 \mathrm{ps}$ and amplifier currents between $100 \mathrm{~mA}$ and $160 \mathrm{~mA}$ the model predicts stable modelocking with a pulse width between $3 \mathrm{ps}$ and $8 \mathrm{ps}$. When the amplifier currents are above $180 \mathrm{~mA}$ the model shows self-pulsation.

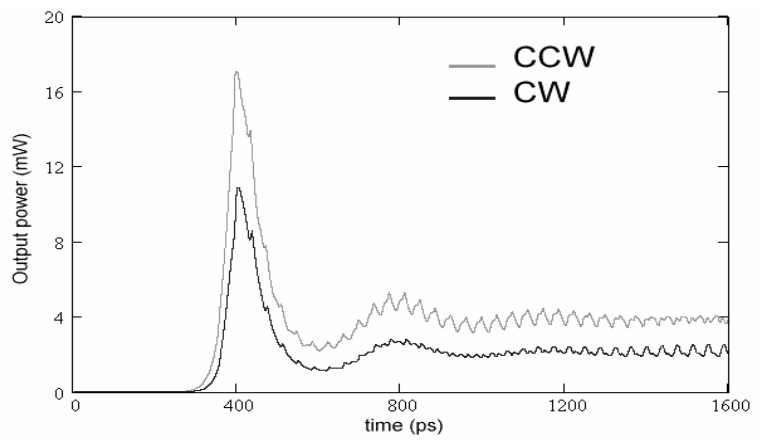

Fig.4: Simulation result of the self-starting MLL at $\mathrm{I}=140 \mathrm{~mA}$ and $\mathrm{T}_{\text {car }}=20 \mathrm{ps}$

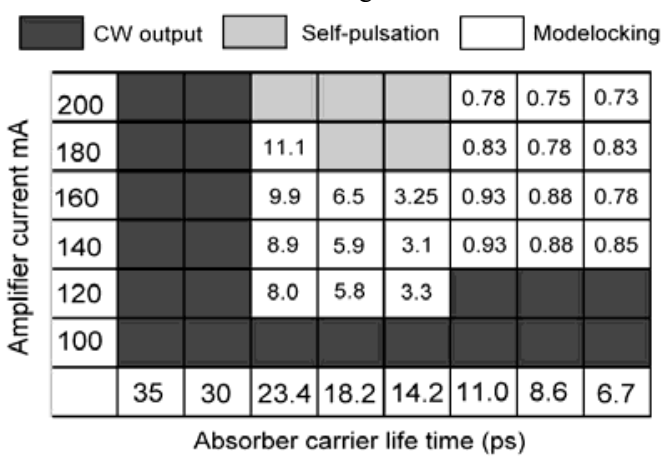

Fig.5: Simulated regimes of operation of the MLL 


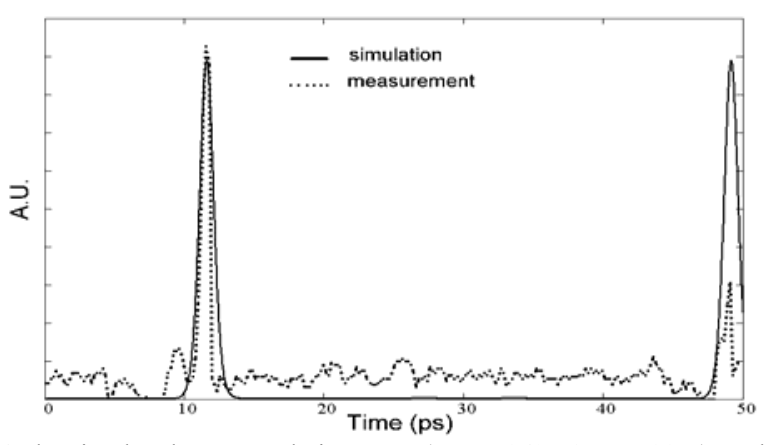

Fig. 6 The simulated autocorrelation trace (Iamp $\left.=160 \mathrm{~mA} \mathrm{~T} \mathrm{~T}_{\mathrm{car}}=11 \mathrm{ps}\right)$, and the measured autocorrelation trace $\mathrm{I}=169 \mathrm{~mA} \mathrm{~V}=-2.1 \mathrm{~V}$

Below 11 ps absorber carrier lifetime the model predicts pulses shorter than $1 \mathrm{ps}$. We consider the model not to be valid in this region because of the approximations made.

A pulse length close to $1 \mathrm{ps}$ has been observed (Fig. 6) when the laser was in an intermittent modelocked state for periods of one to a few seconds. This operating point was at the maximum current and maximum reverse bias voltage. Looking at Fig. 5, the observation of $1 \mathrm{ps}$ at $169 \mathrm{~mA}$ agrees with the model for an absorber carrier life time between 14 and $11 \mathrm{ps}$. The instability is explained by the fact that we are close to the self pulsating regime. In Fig. 6, the second measured pulse is not fully visible due to a limit of the autocorrelator.

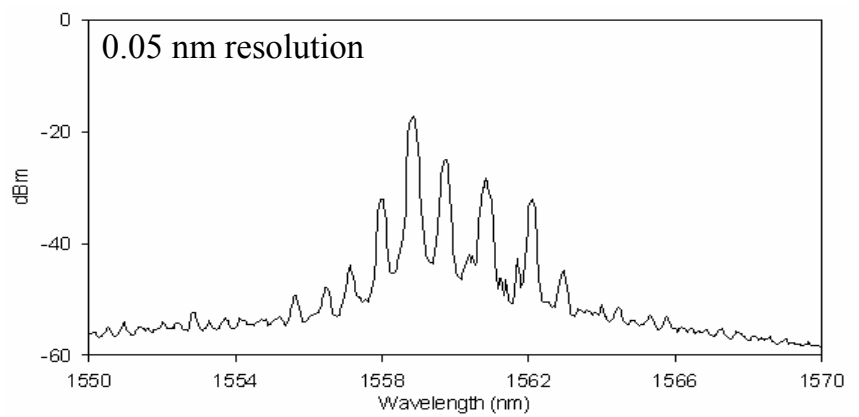

Fig. 7: Optical output spectrum of the laser at $\mathrm{I}=167.5 \mathrm{~mA} V=-2.0 \mathrm{~V}$.
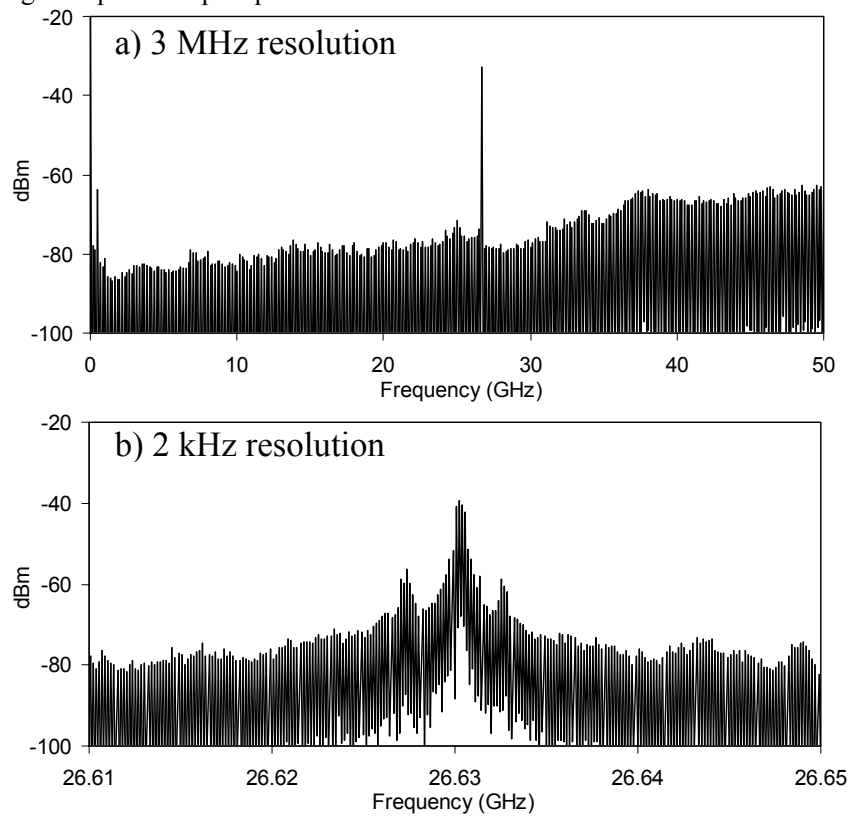

Fig. 8: Measured RF-spectrum $\mathrm{I}=167.5 \mathrm{~mA} \mathrm{~V}=-2.0 \mathrm{~V}$ (a) and (b) figure
An operating point that was stable over 5 minutes has been found. We interpret it as a situation where the cavity contains 5 pulses with a $26.6 \mathrm{GHz}$ modulation. The optical output spectrum is plotted in figure 7. The RF spectra are in Fig. 8a and Fig. 8b. A strong peak ( $40 \mathrm{~dB}$ over the noise floor) that is narrow $(2 \mathrm{MHz}$ at $20 \mathrm{~dB}$ ) is observed at $26.6 \mathrm{GHz}$. This indicates modelocking. The spacing between most of the modes in the optical spectrum is $133 \mathrm{GHz}$, indicating there are five pulses in the cavity with a $26.6 \mathrm{GHz}$ modulation over it. We attribute the generation of the five pulses to the intracavity reflections at the left butt-joint of the amplifier and the upper butt-joint of the absorber. The distance between these two reflections corresponds to one fifth of the cavity roundtrip time. We have attempted to recreate reproduce this regime in our model. A 5 pulses mode was found that was stable for $3 \mathrm{~ns}$ ( 80 roundtrips), but then one of the pulses became dominant and suppressed the other pulses.

\section{CONCLUSION}

We have presented the first integrated extended cavity passively modelocked ring laser using active-passive integration and its modeling. Experimental results show that intra-cavity reflections make it difficult to reach a stable modelocked state. However in small windows of operation modelocked regimes have been observed. The model predict much wider operating windows. However the observed modelocking point is in line with the model predictions.

\section{ACKNOWLEDGMENT}

This research is supported by the Towards Freeband Communication Impulse program of the Dutch Ministry of Economic Affairs and the NRC Photonics program.

\section{REFERENCES}

[1] J.J.M. Binsma, M. van Geemert, F. Heinrichsdorf, T. van Dongen, R.G. Broeke, and M.K. Smit, "MOVPE waveguide regrowth in InGaAsP/InP with extremely low butt joint loss," in Proc. IEEE/LEOS Symp. Benelux Chap. pp. 245-248, 2001

[2] J. Leuthold, R. Hess, J. Eckner, P. A. Besse, and H. Melchior "Spatial mode filters realized with multimode interference couplers", Opt. Lett. 21, 1996, pp 836-838

[3] Y. Barbarin, E.A.J.M Bente, C. Marquet, E.J.S Leclère, M.K. Smit and J.J.M. Binsma "Measurements of Reflectivities on Butt-Joint Active-Passive Interfaces in Extended Cavity Fabry-Pérot Lasers" in Proc. IEEE/LEOS Benelux Chap. (2004)

[4] D. Erasme, L.H. Spiekman, C.G.P. Herben, M.K. Smit, and F.H. Groen, "Experimental assessment of the reflection of passive multimode interference couplers" IEEE Photon. Technol. Lett., vol. 9, no. 12, Dec. 1997, pp. 1604-1606

[5] T.A. DeTemple, C.M. Herzinger, "On the semiconductor laser logarithmic gain-current density relation" IEEE J.Q.E. vol 39. 1933 pp 1246-1252 